People who take TB drugs feel better within weeks, but they have to continue to take the pills for the full six months to get rid of bacteria that may be lying dormant in their body.

That's the simple explanation.

In reality, there are several categories of the bacteria in an infected individual that to the average person sound like a string of synonyms: latent, dormant, persistent, nonreplicating, resting, metabolically inactive and quiescent, to name a few. A successful drug combination has to 'sterilize' all these subpopulations to prevent the infection from recurring.

A test called early bactericidal activity can measure whether drugs are effective against the active bacilli. But there is no good way to know whether a particular combination has succeeded in wiping out the more latent bacteria.

When new combinations are tested in trials, to be absolutely sure that drugs have worked, scientists must wait 18 months or longer and watch for a relapse. "Think about it, it's absurd," says Maria Freire, president and chief executive officer of the New York-based Global Alliance for TB Drug Development.

Because those trials also require large numbers of participants, the costs of following them quickly add up to about $\$ 50$ million for each trial. "Those become expensive trials," says Burman. "For moving the field forward, to find out which dose, which combination of drugs, you can't use that [endpoint], you have to use something else."

At least up to the final stage, a large phase 3 trial, researchers should rely on the drugs' ability to kill active bacteria, Burman says. Only drugs that make it through on that basis should be tested further.

The US National Institute of Allergy and Infectious Diseases, the largest source of money for $\mathrm{TB}$ research, is funding projects to test other markers that could substitute for sterilizing activity, although none have yet been validated. "TB trials need a lot more thinking," says Christine Sizemore, acting chief of TB, leprosy and other mycobacterial infections at the institute.

\section{Resistance and red tape}

Scientists who want to test drugs for MDR-TB, which doesn't respond to the most common treatments, face even bigger challenges.

About 450,000 new cases of MDR-TB are detected each year, but no drug has ever been properly tested for treating it. Although all drugresistant strains are lumped under the umbrella of MDR-TB, there is huge variability among individuals and the bacterial strains they carry.

The only way to characterize resistance is to culture the bacteria, but labs in most African countries don't have the necessary equipment.

\title{
Spotlight on... Mario Raviglione
}

When Mario Raviglione joined the World Health Organization (WHO) in 1991, tuberculosis (TB) control was a global patchwork of ineffective treatments, poor surveillance and disconnects between researchers, doctors and health agencies. Some countries ignored TB altogether.

Much has changed 16 years on. The WHO's main strategy against TB, directly observed treatment short-course, or DOTS for short, was launched in 1995 and is being implemented in 183 countries. Case detection rose from $12 \%$ in 1995 to $53 \%$ in 2004, and yearly TB deaths dropped from 3 million to about 2 million.

But Raviglione, who became director of the WHO's Stop TB department in 2003, says this is just the start. When others in the global health community were content with DOTS, he was already pushing for more. "In the beginning, the focus was on DOTS," Raviglione says. "People would say, 'Don't insist on anything else, because we have to do the basics first."

Under the new Stop TB strategy, DOTS is one element of a much larger plan. The strategy addresses problems DOTS ignores, such as the rapid spread of TB in those infected with HIV and the disconnect between researchers and public health officials. It also asks companies and local communities to play a larger role in TB control.

"DOTS was a biomedical intervention," Raviglione says. "This is a health system intervention."

Much of the new strategy is uncontroversial, but convincing the TB and HIV public-health communities to cooperate may prove difficult. Raviglione, who started out in HIV research, says those in charge of fighting HIV haven't yet acknowledged "that TB kills up to half their patients."

"If only one community pushes it, and you're talking about joint interventions that require participation from doctors in programs dealing with both," says Raviglione, "you can't do anything."

Brandon Keim, New York

For example, there's only one lab in Kenya that can grow cultures. Trials would also need trained research assistants, rather than nurses, to guarantee scientific rigor.

The lack of infrastructure and trained personnel is a pervasive problem in many African countries. In Rwanda, for example, the national ethics office is a single, sparsely furnished room. In South Africa, one informed consent described a strain as "made from the bark of a tree in Japan" because the Afrikaans word for strain was the same.

Navigating the ethics boards in such countries can be particularly time-consuming.

For one Brazilian study, led by Chaisson and his colleagues, the researchers first submitted their proposal in February 2005. Getting Brazil's local and national institutional review boards and the drug approval agency to review the application took 16 months, hundreds of hours of paperwork and two flights to Brasilia to lobby in person. The trial finally began in May 2006.

Even in the US, the regulatory requirements are exhaustive and exhausting, and often more complicated than they need to be.

Chaisson once got a trial application back from the NIH with 178 comments. The second version, which had complied with the first round of queries, came back with 120 comments.
"The regulatory process is a real killer and unbelievably bureaucratic," he says.

As frustrating as these obstacles can be, however, the real tragedy is that they further delay urgently needed new drugs and diagnostics, Chaisson says. "In the 16 months our [Brazil] study was delayed, 2.5 million died of TB."

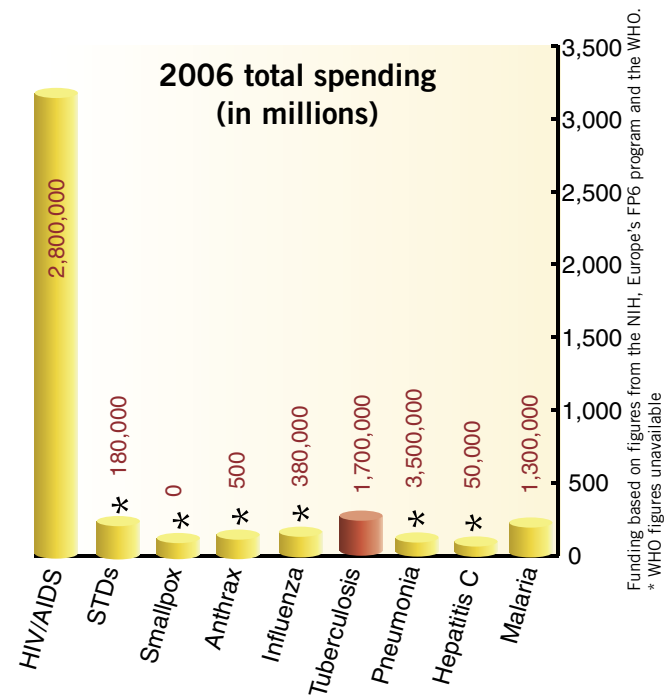

Empty coffers: The global funding for tuberculosis is less than for anthrax or smallpox, although those diseases kill far fewer people (see numbers in red, above). 